\title{
Os benefícios da utilização das TIC no Ensino Superior: a perspetiva docente na E-Learning
}

\section{The benefits of using ICTs in Higher Education: the teacher's perspective on E-Learning}

\author{
Rui Trindade ${ }^{1}$
}

\begin{abstract}
RESUMO
Este é um artigo através do qual se analisam os projetos que receberam o prémio Excelência E-Learning da Universidade do Porto (Portugal), atribuído entre 2004/2005 e 2010/2011, a partir dos benefícios que os docentes atribuíam à utilização das novas Tecnologias de Informação e Comunicação (TIC) como suportes de iniciativas pedagógicas em contextos de formação relacionados com o Ensino Superior. Trata-se de um estudo onde se conclui que estamos perante um campo marcado por tensões, equívocos e contradições diversos, o que tem mais a ver com os pressupostos concetuais e epistemológicos das abordagens pedagógicas que, hoje, têm lugar no Ensino Superior do que propriamente com a reflexão específica sobre a utilização das TIC num tal contexto, a qual é afetada pelo modo como aquelas abordagens são construídas.
\end{abstract}

Palavras-chave: pedagogia no ensino superior; TIC; inovação pedagógica.

\begin{abstract}
This is an article through which we analyze projects that received the E-Learning Excellence Award of Porto University (Portugal), between 2004/2005 and 2010/2011, in order to understand which are the benefits that teachers assigned to Information and Communication Technologies (ICTs) as devices of educational initiatives related to Higher Education. It is a study
\end{abstract}

DOI: $10.1590 / 0104-4060.38661$

1 Universidade do Porto, Faculdade de Psicologia e de Ciências da Educação. Porto, Portugal. Rua Alfredo Allen, 4200-135. 
which concludes that this is a field affected by several kinds of tensions, misunderstandings and contradictions, which has more to do with conceptual and epistemological assumptions about pedagogical approaches in Higher Education today than properly with some specific reflection on the use of ICTs in that context, which is affected by how those approaches are built.

Keywords: pedagogy in higher education; ICT; pedagogical innovation.

\section{Introdução}

A opção, subjacente à elaboração deste texto, que conduziu a identificar os benefícios da utilização das TIC em contextos de formação relacionados com o Ensino Superior explica-se, em primeiro lugar, pelo facto de termos tido acesso a projetos de intervenção que foram considerados por " [...] docentes e investigadores da Universidade do Porto, especialistas em áreas diversas (Ciências da Educação, Tecnologias, Design, Comunicação, ...)" (LEITE; LIMA; MONTEIRO, 2009, p. 73) como expressão de iniciativas pedagógicas de referência no domínio específico das práticas de e-learning e de b-learning. Daí a importância da reflexão e testemunhos que esses projetos divulgam, os quais terão que ser entendidos como o resultado de uma iniciativa do Instituto de Recursos e Iniciativas Comuns da Universidade do Porto (IRICUP), o prémio Excelência E-Learning da Universidade do Porto, "[...] com o objetivo de dinamizar a utilização das TIC, em particular da Internet, no processo de ensino-aprendizagem, através da criação de uma componente on-line de apoio às aulas presenciais" (LEITE; LIMA; MONTEIRO, 2009, p. 73).

\section{Metodologia}

Tendo em conta o objetivo selecionado para promover a análise dos onze relatórios assumiu-se, então, uma opção de caráter metodológico que conduziu a uma primeira leitura global dos documentos citados, em função da qual se alicerçou a operação posterior que consistiu na identificação de macrocategorias construídas a partir das respostas que, a partir da leitura dos relatórios, se encontraram perante o seguinte conjunto de questões: (i) Quais as expectativas dos professores relativas à utilização das TIC como suporte de iniciativas referentes 
à organização e gestão do processo de ensino-aprendizagem? (ii) Que tipos de relação se podem estabelecer entre a utilização das TIC e os objetivos das unidades curriculares que os professores lecionam? (iii) Quais as iniciativas que foram concretizadas? (iv) Quais os sentidos das avaliações produzidas? (v) Até que ponto há referência aos ciclos didáticos mais amplos onde se enquadram os diferentes tipos de utilização das TIC como instrumentos de ação pedagógica?

Foi a partir dos dados obtidos que se pôde estabelecer um conjunto de interrogações e de interpelações que esteve na base do processo de interpretação dos referidos dados, o qual se foi consolidando à medida que as interpretações foram sendo explicitadas e testadas, confrontando as explicações encontradas com outras explicações alternativas de forma a conferir uma maior coerência e credibilidade ao exercício de análise. Um exercício que se constrói através da leitura dos já referidos onze relatórios, referentes a outros tantos projetos, cuja identificação e descrição sumárias podem ser consultadas no Anexo 1, e que se publica neste texto através da abordagem de três temáticas principais: (i) A articulação entre os objetivos das unidades curriculares e os projetos de "e-learning" ou de "b-learning"; (ii) A utilização das TIC como instrumentos de intervenção em ciclos didáticos mais amplos; e (iii) A função pedagógica das TIC: Entre a eficiência e a inovação pedagógica. Temáticas estas que correspondem ao processo de reflexão que nos propusemos realizar, através do qual se visava identificar quais os benefícios que nos projetos vencedores do prémio Excelência E-Learning da Universidade do Porto se atribuem à utilização das TIC como suportes de iniciativas pedagógicas em contextos de formação relacionados com o Ensino Superior, de forma a explorar as expectativas e as representações que aí se manifestam acerca das potencialidades pedagógicas das TIC. Um exercício cuja importância tem a ver, entre outras razões passíveis de ser elencadas, com o facto de estarmos perante projetos, que ao serem objeto de reconhecimento público, por parte de especialistas, podem ser entendidos como documentos que exprimem uma reflexão credível e pertinente que importa valorizar.

Dos onze projetos selecionados, dois deles poderão ser identificados como projetos curricularmente delimitados, do ponto de vista da utilização das TIC, tendo em conta que um deles descreve e analisa as potencialidades quer de um jogo virtual, que permite compreender como o sistema imunitário se desenvolve, quer dos "quizzes" em função dos quais se avalia o impacto do jogo ao nível das aprendizagens dos alunos (MOREIRA et al., 2009), enquanto o outro diz respeito à preparação e realização de testes de escolha múltipla através da utilização de computadores, de forma a garantir a equidade do processo avaliativo (MOURA; AMARAL; SEVERO, 2011). Os restantes nove projetos são projetos em que as TIC foram mobilizadas, ainda que de forma diferenciada, para que os estudantes tivessem que realizar os mais diversos conjuntos de tarefas académicas. 


\section{A articulação entre os objetivos das unidades curriculares e os projetos de "e-learning" ou de "b-learning"}

A análise do tipo de articulação que nos projetos se estabelece entre os objetivos curriculares destes projetos e a utilização das TIC corresponde a uma decisão em função da qual se esperaria identificar até que ponto uma tal utilização é circunscrita ou periférica ou, pelo contrário, tende a constituir-se como uma opção que afeta a organização e gestão do trabalho pedagógico no âmbito de cada uma das unidades curriculares relacionadas com aqueles projetos.

Neste domínio, analisamos, apenas, nove dos onze projetos selecionados, na medida em que os dois projetos atrás identificados como projetos curricularmente delimitados, do ponto de vista da utilização das TIC, exprimem, dada a sua natureza, uma utilização pedagógica circunscrita destas tecnologias. Por isso, foram os restantes projetos que se constituíram como objeto da nossa atenção, sendo possível constatar que tendo em conta os objetivos enunciados, a utilização das TIC, que chega a ser um objetivo explicitamente assumido nos programas de duas das unidades curriculares estudadas (MOREIRA; TEIXEIRA; VALENTE, 2005; RIBEIRO et al., 2008), justifica-se em função da necessidade de se:

a) alargar e diversificar as fontes de informação disponíveis (MOREIRA; TEIXEIRA; VALENTE, 2005);

b) assumir uma outra atitude pedagógica que permita "[...] ultrapassar algumas das limitações do ensino tradicional" (MOREIRA; TEIXEIRA; VALENTE, 2005, p. 7), nomeadamente aquelas que têm a ver com a importância excessiva dos conteúdos relativamente aos processos, a valorização da memorização a curto prazo, a desvalorização da utilidade das informações divulgadas, a centralização do trabalho pedagógico na figura do professor e a desvalorização do papel que os estudantes poderão assumir como gestores das suas aprendizagens (MOREIRA; TEIXEIRA; VALENTE, 2005);

c) criarem as condições que permitam concretizar o desenvolvimento das competências previstas nas unidades curriculares (MOREIRA; TEIXEIRA; VALENTE, 2005; FERREIRA; AMARAL, 2009);

d) criar as condições para que os estudantes, através dos fóruns de discussões, dos "chat" ou, entre outros, do correio eletrônico possam ter uma participação mais dinâmica nas aprendizagens que lhes dizem respeito e na monitorização das mesmas (MOREIRA; TEIXEIRA; VALENTE, 2005; FERREIRA; AMARAL, 2009);

e) prolongar o trabalho de aprendizagem para além dos tempos letivos (MOREIRA; TEIXEIRA; VALENTE, 2005); 
f) estabelecer uma relação congruente entre os desafios e as exigências científicas e os desafios e as exigências pedagógicas das unidades curriculares (VILLATE, 2005).

Noutros projetos, os autores não estabelecem nenhuma articulação explícita entre os objetivos das unidades curriculares e a utilização das TIC, ainda que seja possível inferir a possibilidade de uma tal articulação no caso dos projetos de Ribeiro e colaboradores (2008) e de Oliveira (2008). Finalmente, há um projeto, de Remião (2007), que no plano de estudos se revelam três componentes: (i) a componente teórica; (ii) a componente laboratorial; e (iii) a componente "e-learning" como componentes que se correlacionam entre si.

Sendo possível concluir que a utilização das TIC é assumida nos diferentes projetos, de forma mais ou menos explícita e pelas mais diversas razões, como uma componente a ter em conta nas dinâmicas pedagógicas que os mesmos descrevem, importa, agora, aprofundar o debate através da mobilização da noção de ciclo didático, em função do qual se visa tentar compreender como é que as TIC se enquadram num conjunto de atividades ordenadas que se estruturam de forma articulada para se poderem cumprir determinados objetivos educacionais, podendo conferir-lhes sentidos e impactos formativos distintos. Trata-se de uma noção que deriva de uma outra noção congénere, da autoria de Zabala (1998), a noção de "sequência didática", da qual se distingue pelo facto de se pretender acentuar a contingência de um processo didático onde coexiste uma zona de impactos formativos.

\section{A utilização das TIC como instrumentos de intervenção em ciclos didáticos mais amplos}

Do conjunto dos projetos em análise confirma-se, de imediato, que nos dois projetos curricularmente delimitados, do ponto de vista da utilização das TIC (MOREIRA et al., 2009; MOURA; AMARAL; SEVERO, 2011), não há qualquer referência à articulação entre os dispositivos que os mesmos propõem e o ciclo didático onde tais projetos se enquadram, o que é uma situação expectável dada a natureza pedagogicamente circunscrita dos referidos projetos.

Dos restantes projetos, identifica-se, como já foi referido, um projeto (VILLATE, 2005) onde não havendo propriamente uma reflexão explícita sobre o enquadramento das TIC num determinado ciclo didático, há, em alternativa, uma reflexão clara sobre a necessidade de se estabelecer uma relação cientificamente congruente entre a utilização das TIC e as opções epistemológicas 
que sustentam os objetivos formativos da unidade curricular em questão. Para além deste projeto há outros dois (REMIÃO, 2007; OLIVEIRA, 2008) em que a estratégia argumentativa utilizada pelos seus autores tende a isolar a identificação e a reflexão sobre a componente do "e-learning" face às restantes iniciativas pedagógicas que se promovem no âmbito das respetivas unidades curriculares. Não se pode concluir que não há articulação entre aquela componente e estas iniciativas, mas tão somente que uma tal articulação não é objeto de qualquer tipo de explicitação ou de reflexão teóricas. O que se constata é que tanto num como noutro projeto a descrição das iniciativas referentes às práticas de "e-learning" são claras, criteriosas e fundamentadas, como se a maior preocupação dos seus autores fosse, sobretudo, a de conferir visibilidade a tais práticas, o que poderá explicar a ausência de qualquer tipo de referência aos ciclos didáticos onde tais práticas poderiam ser enquadradas.

Nos restantes seis projetos analisados identificam-se aqueles projetos (ANDRADE; VALENTÃO; AMARAL, 2006; VASCONCELOS, 2006; FERREIRA; AMARAL, 2009) em que os seus autores afirmam que a utilização das TIC, nas suas mais diversas manifestações, visa assumir um papel complementar face à componente presencial ou ao trabalho dos estudantes nos laboratórios. Por fim, identificam-se os projetos desenvolvidos por Moreira, Teixeira \& Valente (2005), por Ribeiro e colaboradores (2008) e por Payo-Puente (2010), em que a reflexão sobre o enquadramento das TIC no âmbito do ciclo didático apresenta algumas especificidades sobre as quais vale a pena refletir.

No caso do projeto dinamizado por Moreira, Teixeira \& Valente (2005, p. 3), importa valorizar a referência ao "blended learning" para que se "[...] compreenda melhor a estratégia de integração da componente on-line com a componente tradicional". A reflexão sobre o método expositivo e o modo como este se articula com a aprendizagem através da resolução de problemas, o estudo de casos, a análise de artigos ou, entre outros, a análise de pareceres técnicos, bem como as discussões on-line sobre as soluções encontradas, os casos, os artigos e os pareceres, o que constitui a expressão de uma abordagem onde a utilização dos repositórios e dos fóruns on-line se enquadram no âmbito de ciclos didáticos mais amplos.

Por sua vez, no projeto que Ribeiro e colaboradores (2008, p. 3) animaram, refere-se explicitamente que se visa promover a transformação "[...] de repositório a estação de treino virtual", na medida em que se pretende que "o desenvolvimento do "pensamento anatómico"" conduza ao desenvolvimento do “"pensamento clínico"” (RIBEIRO et al., 2008, p. 3).

Finalmente, no projeto de Payo-Puente (2010, p. 8), onde se divulgam as três etapas de uma estratégia intencional "[...] de integração da componente on-line com a componente presencial", as TIC, a exemplo dos outros projetos 
acabados de referir, estão longe de poder ser entendidas como tecnologias complementares das aulas presenciais. Neste projeto, a componente on-line é uma componente decisiva do desenvolvimento de iniciativas centradas em experiências reais, constituindo condição de uma atividade onde o protagonismo e a autonomia dos estudantes assumem um papel decisivo quer do ponto de vista da procura de recursos, da decisão face a opções diversas que se poderiam assumir, da discussão destas opções, da divulgação e discussão dos resultados e da avaliação do trabalho realizado.

Como se constata, perante estes três projetos, as TIC estão longe de poder ser entendidas, apenas, em função de um papel de caráter instrumental. Isto é, para estes projetos as TIC não se limitam a servir, apenas, de complemento às aulas presenciais ou a ampliar a sua influência e os seus efeitos, como no caso do projeto de Andrade, Valentão \& Amaral (2006), em que a utilização da plataforma virtual é vista "como um prolongamento" da sala de aula ou no projeto de Ferreira \& Amaral (2009, p. 7), onde a estratégia adotada “[...] incluiu aulas teóricas complementadas com a componente on-line e ensino tutorial, assim como aulas laboratoriais" ou, ainda, no projeto de Vasconcelos (2006, p. 2) que considera que "[...] uma abordagem e-Learning complementar às aulas presenciais significa uma mais valia quer pela disponibilidade temporal quer pela potencialidade em motivar alguns alunos", na medida em que "[...] há muito material de grande valor educativo e que por falta de tempo não pode ser apresentado e discutido nas aulas" (VASCONCELOS, 2006, p. 2).

Em suma, como se constata, a análise dos textos revela-nos várias possibilidades de entender o papel das TIC como instrumento de formação académica. Assim, no caso dos projetos analisados, defrontamo-nos com aqueles que utilizam as TIC como instrumentos de formação, entendidos como relevantes, ainda que pedagogicamente periféricos. Noutra perspetiva, tomamos contato com outros projetos que abordam as TIC como instrumentos subsidiários de iniciativas pedagógicas que continuam a subordinar-se às aulas presenciais. Finalmente, uma terceira perspetiva é aquela em que as TIC são abordadas como um polo estruturante da organização e gestão do trabalho pedagógico a desenvolver que, podendo coexistir com outras modalidades de ação pedagógica, nem se subordina a estas modalidades nem tão pouco as subordina.

Se esta reflexão nos permite compreender o valor funcional das TIC como instrumento de ação pedagógica, importa refletir sobre os sentidos pedagógicos da utilização destas tecnologias, na medida em que, de acordo com uma perspetiva que se afasta da racionalidade tecnocrática, não é possível abordar tais sentidos a partir, apenas, da revelação do seu valor funcional. Será no próximo subcapítulo que esta questão se tornará objeto de reflexão neste texto, beneficiando quer da análise e discussão dos dados que temos vindo a apresentar quer, 
ainda, da análise dos dados referentes às expectativas dos autores dos projetos, bem como às realizações dos mesmos.

\section{A função pedagógica das TIC: Entre a eficiência e a inovação pedagógica}

A reflexão sobre os sentidos e o impacto pedagógicos da utilização das TIC como instrumentos de formação é, neste texto, uma reflexão obrigatória, dado o vínculo que os projetos a que tivemos acesso estabelecem, de forma mais ou menos explícita, entre essa utilização e uma alegada mudança das práticas pedagógicas dos docentes. Trata-se de um fenómeno que terá que ser explicado, em primeiro lugar, à luz da influência do processo de reorganização do espaço europeu do ensino superior que o processo de Bolonha consagrou. Um processo que, pelo menos do ponto de vista das narrativas que o enformam, adquire visibilidade, entre outras razões passíveis de elencar, por via da centralidade pedagógica que defende que os estudantes deverão assumir na gestão e desenvolvimento dos projetos de formação que lhes dizem respeito. Uma reivindicação que nos projetos analisados está presente, de um modo geral, na valorização da necessidade de se estimular a atividade intelectual dos alunos e, de forma mais específica, na reivindicação do desenvolvimento de competências relacionadas com o exercício da profissão e o confronto com os problemas que decorrem deste mesmo exercício (VASCONCELOS, 2006; RIBEIRO et al., 2008; REMIÃO, 2007; OLIVEIRA, 2008; FERREIRA; AMARAL, 2009; PAYO-PUENTE, 2010). Diríamos, em síntese, que as narrativas através das quais se visa justificar a mobilização para projetos que impliquem a utilização das TIC se prendem com a necessidade de superar o que poderá ser considerado uma abordagem escolástica da formação que tem lugar no Ensino Superior.

Resta saber, no entanto, se a utilização das TIC como instrumento pedagógico, só por si, favorece a possibilidade de concretizar um tal objetivo e, também, como é que os diferentes projetos se propõem concretizar o mesmo.

Numa leitura global destes projetos poderemos considerar que há duas perspetivas distintas de abordar a problemática em questão, através das quais se confrontam quer a necessidade de ser pedagogicamente eficiente quer a necessidade de se promover projetos de inovação pedagógica. Trata-se de perspetivas que não só se distinguem entre si quanto às estratégias que mobilizam como, igualmente e sobretudo, face aos propósitos que as configuram, ainda que se admita que o "[...] caráter sedutor e inovador da palavra inovação" (CORREIA, 
1989 , p. 26) possa contribuir para ocultar o que diferencia os projetos que se encontram preocupados, acima de tudo, com mudanças processuais e os projetos que visam provocar ruturas pedagógicas, a partir do estabelecimento de ruturas epistemológicas e concetuais. Tal como defende Correia (1989, p. 27) "[...] tende-se, de facto, a confundir a inovação com a evolução 'natural' das práticas pedagógicas", confundindo-se, assim, mudança com inovação ou, em último caso, promovendo-se "[...] uma visão instrumental da inovação" (CORREIA, 1989, p. 28). Uma visão que, para Correia (1989, p. 28), se define como uma transformação que supõe, apenas e sobretudo, “[...] não só uma mudança de materiais, mas também um conjunto complexo de mudanças quanto à sua utilização" que, tendo em conta a análise de alguns dos projetos, se justifica por via da necessidade de se: (i) melhorar e facilitar o acesso aos documentos e materiais de trabalho e de estudo; (ii) estimular uma maior eficiência e produtividade do trabalho académico realizado pelos estudantes; (iii) contribuir para uma ação pedagógica mais eficiente por parte dos professores; e (iv) intervir, de forma mais eficaz, no processo de avaliação. Resta saber, no entanto, se estas mudanças geram algum tipo de inovação pedagógica.

O que se pergunta, por isso, é se os projetos que propõem mudanças que visam "[...] complementar o modelo tradicional de ensino com a introdução de novas tecnologias" (VASCONCELOS, 2006, p. 3) garantem que, só por si, o estatuto de menoridade pedagógica dos estudantes, o qual carateriza as pedagogias da instrução (TRINDADE; COSME, 2010), sofra alterações substanciais?

Pergunta-se, também, se a utilização das TIC como um estímulo a uma maior eficiência e produtividade do trabalho académico dos estudantes, através da organização de "[...] formas mais eficientes de promover a aprendizagem contínua" (OLIVEIRA, 2008, p. 4) ou da inclusão, "na parte on-line do curso" (VASCONCELOS, 2006, p. 4) dos enunciados dos exercícios e da exemplificação "[...] das resoluções de alguns problemas devidamente tipificados" (VASCONCELOS, 2006, p. 4) assegura que os alunos passam a ter um outro tipo de protagonismo no âmbito do processo de formação que lhes diz respeito?

Pergunta-se, finalmente, se é o facto dos docentes ficarem disponíveis em "[...] horários antes impensáveis, nomeadamente à noite e aos fins-de-semana" (ANDRADE, VALENTÃO; AMARAL, 2006, p. 2) ou conseguirem uma gestão mais eficaz do "[...] tempo dispendido com o acompanhamento dos estudantes" (OLIVEIRA, 2008, p. 4), fruto da centralização de "[...] dúvidas, discussões, correções e variados aspectos de funcionalidade (trocas de turmas, avisos, marcações de exames e respectivas consultas, etc.) na página de e-learning" (OLIVEIRA, 2008, p. 4) que favorecem, igualmente, um tal protagonismo?

O que se constata é que mais do que o protagonismo discente o que parece pretender-se garantir é a condução e o controlo, por parte dos professores, de 
um projeto de formação bem-sucedido, como se torna possível constatar pela análise de resultados do projeto de Andrade, Valentão e Amaral (2006), em que o Fórum foi a ferramenta com maior utilização por parte dos alunos, cerca de $40 \%$ do total das sessões on-line, seguido do Content File e, em terceiro lugar, da ferramenta Who's on line? Três ferramentas que contribuem para suportar o pressuposto atrás referido, no momento em que se afirma, no projeto em causa, que o Fórum é um espaço onde os estudantes apresentam e colocam à discussão as pesquisas que realizaram, enquanto estratégia concebida pelo professor para melhorar a preparação destes estudantes para o exame laboratorial. A ferramenta Content File permite que os alunos encontrem aí "todo o material relativo às aulas" (ANDRADE; VALENTÃO; AMARAL, 2006, p. 4), enquanto a Who's on line é valorizada como um instrumento que serve "[...] para encontrar o professor, o que foi muitas vezes conseguido" (ANDRADE; VALENTÃO; AMARAL, 2006, p. 4). É também a preocupação com a criação de situações que assegurem a produtividade académica dos estudantes, por via de uma gestão adequada dos dispositivos pedagógicos que se constroem através da utilização das TIC, que se manifesta no projeto de Ribeiro e colaboradores (2008, p. 8), onde através da plataforma virtual se pretende que "[...] os estudantes se preparem antecipadamente para as aulas, lendo os textos de apoio aconselhados e, no caso dos casos clínicos, respondendo às questões previamente colocadas e trazendo para as sessões os pontos de discussão levantados por cada caso clínico". Uma perspetiva que se defende, igualmente, no projeto de Vasconcelos (2006, p. 3) quando se afirma que uma das razões que motivou o autor a desenvolver o projeto teve a ver com o facto deste "[...] permitir que o processo de aprendizagem fosse contínuo".

Constata-se, assim, que a eficiência da ação docente é um dos eixos dos discursos que visam legitimar a utilização das TIC como instrumento de ação pedagógica, seja através da valorização dos repositórios virtuais, seja através da possibilidade de potenciar a produtividade do trabalho académico dos estudantes, tanto por via de dispositivos de controlo mais eficazes como de um tipo de disponibilidade docente inédita que as TIC permitem assegurar. Afirma-se, assim, uma perspetiva referente à utilização pedagógica das TIC que, neste trabalho, passará a ser designada por perspetiva eficienticista.

Se o vínculo entre a utilização pedagógica das TIC e a eficiência pedagógica é uma das caraterísticas da perspetiva eficienticista, importa reconhecer que, a julgar pela análise dos projetos que realizamos, esta perspetiva não se limita a conferir visibilidade, somente, a esse vínculo. Este é um elemento nuclear da perspetiva eficienticista, o qual, no entanto, não poderá deixar de ser compreendido em função de uma outra dimensão: a da hipervalorização da componente 
técnica das ações que se promovem, como se esta componente garantisse, só por si, a sua indiscutibilidade do ponto de vista pedagógico.

Uma dimensão que está presente no texto referente ao projeto de Oliveira (2008, p. 3), onde se descreve e discute o papel das TIC como instrumento capaz de potenciar a colaboração entre pares. É nesse texto que se considera que "[...] as interacções entre os estudantes no contexto da disciplina, as vantagens da resolução de problemas em conjunto, a partilha de experiências e a intercomunicação" constituem uma oportunidade de aprender com os pares, a qual "[...] é complementar à aprendizagem com o professor" (OLIVEIRA, 2008, p. 3-4). Uma afirmação que nos obriga a perguntar o que é que se entende por aprender no texto em causa e o que significa afirmar que a aprendizagem entre pares é complementar das aprendizagens que acontecem com os professores. Só respondendo a estas questões é que se torna possível identificar que tipos de vantagens académicas é que os estudantes obtêm quando resolvem problemas em conjunto, quando partilham experiências ou quando comunicam entre si. É que tais atividades podem ter significados pedagógicos distintos, podendo assegurar ou o protagonismo dos alunos como interlocutores no processo de apropriação de informações, necessárias ao processo de construção de saberes, ou, apenas, a sua recetividade face às exigências e aos desafios que lhes são prescritos pelos seus professores. Optar por uma ou outra das vias enunciadas tem implicações distintas quanto à função que se atribui às TIC como instrumento de ação educativa, o que significa que, ao contrário do que a perspetiva eficienticista sugere, a pergunta "Como fazer?" não é a única pergunta a formular nem tão pouco é a pergunta mais decisiva. Sem a associarmos a uma outra questão, a do "Por que fazer?", estamos perante uma questão potenciadora de equívocos e de mal-entendidos pedagógicos.

É esta abordagem, alimentada pela perspetiva eficienticista, que determina o modo como o projeto de Moreira e colaboradores (2009) aborda a relação entre a autoaprendizagem e a utilização das TIC. Um projeto onde se compara o impacto de um jogo virtual e das aulas expositivas, de forma a determinar-se qual o método de aprendizagem mais eficaz, através das respostas dos estudantes a perguntas que exigiam que estes fossem capazes de demonstrar se compreendiam o desenvolvimento do sistema imunitário. De acordo com os resultados obtidos, concluiu-se que não havia diferenças significativas entre os dois grupos de estudantes, em termos das respostas às questões que serviram para testar as aprendizagens realizadas, ainda que se tenha considerado que a utilização do jogo virtual e "[...] a divisão dos estudantes em pequenos grupos contribuíram tanto para promover o seu envolvimento e participação na atividade como para fazer aumentar o seu interesse" (MOREIRA et al., 2009, p. 10). Daí a proposta final do grupo de pesquisadores em investirem na criação de mais jogos vir- 
tuais relacionados com as aprendizagens a realizar no domínio da imunologia, o que poderá ser lido como uma proposta através da qual se reconhece que a autoaprendizagem tem um impacto formativo superior às modalidades de ensino onde os professores pontificam, que a centralidade pedagógica destes últimos constitui um obstáculo às autoaprendizagens dos alunos e que as TIC poderão constituir a solução pedagógica ideal tanto para catalisar a atividade e o envolvimento dos alunos em processos de autoprendizagem como para se poder substituir os professores como agentes difusores de informação. Trata-se de um investimento que é equivalente a um outro que teve lugar no projeto de Ferreira e Amaral $(2009$, p. 4), onde se sabe que, para além das páginas HTML construídas "[...] para apoio ao conteúdo dos três capítulos das aulas teóricas e das três séries de trabalhos das aulas laboratoriais" se construíram, pelo menos, dois jogos, um denominado "Distribuição de nutrientes", que é “[...] um jogo que ajuda a compreender e conhecer de forma intuitiva a distribuição das proteínas, lípidos [...], glúcidos, vitaminas e sais minerais em alimentos de origem vegetal e animal", e outro "Dietas à medida", um jogo que "[...] ajuda a organizar um plano alimentar personalizado para indivíduos com diferentes características" (FERREIRA; AMARAL, 2009, p. 4). Jogos estes cuja importância é explicada por via da possibilidade de se realizar "uma aprendizagem mais dinâmica e lúdica", para além de facilitar a "interacção entre estudantes" (FERREIRA; AMARAL, 2009, p. 4).

Numa leitura global dos argumentos, através dos quais se tenta demonstrar como as TIC permitem concretizar a autoaprendizagem, pode considerar-se que há uma ideia nuclear que é transversal aos mesmos, a de que a relação a privilegiar é aquela que se estabelece entre os estudantes e os jogos virtuais, sendo o professor visto como uma espécie de intruso nessa relação. No caso do projeto de Ferreira e Amaral (2009) a eficiência pedagógica é assegurada por via das TIC que, como se demonstra no projeto de Moreira e colaboradores (2009), não permite obter melhores resultados académicos do que as aulas dos professores, ainda que favoreçam, mais do que estas aulas, a atividade e o envolvimento dos alunos.

Não é, no entanto, a eventual maior eficiência das TIC que se discute aqui, mas o modo como através da valorização da eficiência se penaliza a reflexão sobre os sentidos das ações pedagógicas que se propõem. Trata-se de uma problemática que é uma das vulnerabilidades das leituras que a perspetiva eficienticista propõe sobre a utilização das TIC como instrumento de ação pedagógica, nomeadamente quando se induz a possibilidade de contribuir para a desvalorização da ação docente por via da valorização das TIC. Uma posição que, de algum modo, sustenta as propostas que atribuem às TIC, no âmbito do Ensino Superior, uma função pedagógica supletiva, como acontece no projeto 
de Andrade, Valentão e Amaral (2006, p. 13) quando se afirma que a plataforma virtual torna possível "[...] abordar assuntos relacionados com a disciplina, que não seria possível discutir nas aulas teóricas por falta de tempo". Sendo aceitável esta atitude pedagógica, importa discutir, no entanto, em que circunstâncias é que a mesma é desejável, tendo em conta o que se pode ler no projeto de Vasconcelos (2006, p. 2), em que se considera que há “[...] muito material de grande valor educativo e que por falta de tempo não pode ser apresentado e discutido nas aulas" ou quando se valorizam as novas tecnologias educacionais no ensino de Anatomia Clínica, tendo em conta que permitem

[...] ultrapassar os três principais obstáculos à educação anatómica dos estudantes de medicina em Portugal: (i) número insuficiente de cadáveres humanos para as atividades de ensino e de dissecação anatómica; (ii) Dificuldade em atrair pessoal médico qualificado para o ensino da ciência anatómica [...]; (iii) Restrições impostas pela tutela à contratação de docentes (RIBEIRO et al., 2008, p. 16).

E, igualmente, “[...] assegurar que os estudantes de medicina iniciem o treino clínico munidos de competências em Anatomia com preparação suficiente para enfrentar os desafios de uma ciência médica em rápida evolução" (RIBEIRO et al., 2008, p. 16). Como se constata, há um conjunto diverso de razões que se invocam para justificar a importância pedagógica das TIC, que exprimem perspetivas distintas acerca da utilidade das mesmas, no momento em que se enfatiza a possibilidade quer de se ultrapassar dificuldades de caráter logístico, quer de resolver dificuldades referentes à insuficiência de recursos humanos, quer, ainda, de lidar com as dificuldades que emergem tanto da falta de tempo como da falta de oportunidades para se promover projetos de formação mais ambiciosos.

Apesar de tudo, das razões atrás invocadas para valorizar a importância da utilização das TIC, importa compreender que, mais do que as dificuldades logísticas ou a necessidade de promover projetos mais ambiciosos, são as dificuldades relacionadas com a insuficiência de professores que interessa discutir, na medida em que se parece insinuar a possibilidade das TIC superarem tal insuficiência. Uma possibilidade que terá que ser relacionada com a perspetiva, tantas vezes implícita, através da qual se valoriza a importância da utilização pedagógica das TIC como um instrumento capaz de potenciar a autossuficiência pedagógica e cultural dos estudantes. Autossuficiência esta que pode ser definida, hoje, como uma tendência de alguns dos discursos pedagógicos que se 
têm vindo a produzir no Ensino Superior, por força da influência da andragogia (KNOWLES, 1984) e, em geral, pelo peso que o "[...] paradigma pedagógico da aprendizagem" (TRINDADE; COSME, 2010, p. 41) exerce sobre as ideias educativas contemporâneas. Segundo Trindade e Cosme (2010, p. 42), um tal paradigma carateriza-se por entender os estudantes "[...] como o centro de gravidade dos projetos de educação escolar", o que justifica que, nesta abordagem, sejam os dispositivos de mediação pedagógica que "[...] permitem potenciar as aprendizagens dos alunos" (TRINDADE; COSME, 2010, p. 41) que constituem a sua principal preocupação. Daí que a reflexão sobre o papel dos professores tenda a identificar a sua atuação com a de facilitadores pedagógicos, iludindo-se, entre outras coisas, o que Harland designa por "paradoxo do controlo" (HARLAND, 2002, p. 10), quando nos mostra como a autonomia intelectual dos estudantes é uma finalidade que não poderá ser dissociada dos compromissos epistemológicos, das tradições e das exigências das profissões em função dos quais se configuram os planos de estudo dos cursos e, por inerência, o papel dos professores como gestores curriculares e pedagógicos. Ou seja, ainda que o paradigma da aprendizagem tenha assumido um papel historicamente importante na denúncia da menorização dos estudantes como produtores de significados e de saberes, não foi capaz, contudo, de superar o seu registo pedagógico mutualista, acabando por contribuir para subestimar as vicissitudes e os contornos do confronto epistemológico que se estabelece entre os estudantes, enquanto seres pessoal e culturalmente singulares, e a fatia decisiva do património de informações, instrumentos, procedimentos e atitudes cultural e socialmente validados (TRINDADE; COSME, 2010) que as escolas disponibilizam como componente incontornável do processo de formação dos seus estudantes.

Não sendo inevitável que a utilização pedagógica das TIC se subordine a um tal paradigma importa compreender que esta é uma tendência cuja afirmação está presente em alguns dos projetos que analisamos. Não se recusa a possibilidade das TIC poderem assumir uma função pedagógica supletiva, ainda que seja necessário identificar quando é que uma tal função pode corresponder a uma desvalorização do papel dos professores, quer seja por via de políticas educativas de desinvestimento nos recursos humanos que são necessários para promover uma formação de qualidade no Ensino Superior, quer seja por via de conceções que tendem a abordar os estudantes como seres culturalmente autossuficientes.

Numa abordagem distinta, é possível identificar, no entanto, outros tipos de projetos que, dados os seus objetivos e propostas, se considera como pertencentes ao campo da inovação pedagógica quer por proporem ruturas pedagógicas com o "paradigma pedagógico da instrução" (TRINDADE; COSME, 2010, p. 28) quer por superarem alguns dos equívocos apontados ao paradigma da aprendizagem. Não são projetos isentos de contradições e equívocos mas poderão ser 
caraterizados, de um modo geral, como projetos alternativos àqueles que foram analisados até este momento, os quais se subordinam ao que tem vindo a ser designado por perspetiva eficienticista.

O projeto dinamizado por Moreira, Teixeira e Valente (2005) é um projeto onde se explicita de forma clara o enquadramento das TIC no ciclo didático mais amplo através do qual o projeto é dinamizado. Um ciclo didático que se carateriza por valorizar a atividade académica dos estudantes como uma oportunidade de apropriação de informação e construção de saberes, em função de uma relação produtiva, e andaimada pelo professor, com a leitura de artigos publicados em revistas científicas, a concretização de estudos de caso, a resolução de problemas, a organização, por parte dos estudantes, de seminários e todos os subsequentes momentos de partilha que estimulam a colaboração entre os alunos. Não sendo um ciclo didático que se circunscreve à utilização das TIC, não deixa de ser um ciclo que depende das TIC para permitir que aquela atividade académica se concretize, coexistindo com a "exposição dialogada" (MOREIRA et al., 2009, p. 8), a qual é objeto de uma reflexão sobre as potencialidades das sessões expositivas e alguns dos cuidados e procedimentos a respeitar neste âmbito. Acima de tudo, há uma relação coerente entre as atividades propostas, sejam estas de natureza presencial sejam estas realizadas na plataforma virtual, bem como uma explicitação das razões pedagógicas que justificam umas e outras.

Assim, defende-se que as sessões expositivas

[...] podem facultar oportunidades intensas de aprendizagem, nomeadamente para: possibilitar dar informações atualizadas e novas [...] e que muitas vezes não se encontram publicadas [...]; possibilitar saleientar semelhanças e diferenças entre conceitos fundamentais [...]; facilitar a comunicação do entusiasmo dos docentes sobre determinados conceitos; modular a forma como a disciplina lida com determinadas questões de evidência, análise crítica e resolução de problemas; permitir organizar um determinado assunto, selecionando informação de fontes diversas, para que seja melhor adaptada às caraterísticas dos estudantes; salientar conceitos importantes e partilhar visões pessoais sobre aspetos particulares, dando a conhecer o que deve ser aprendido; promover a memorização durante a sessão; possibilitar, mesmo aos estudantes mais solitários ou tímidos, interagirem [...], sentindo-se parte da comunidade e estimulando a coesão do grupo (MOREIRA et al., 2009, p. 8).

A estas sessões acrescentam-se o 
[...] visionamento de filmes; análise de "position papers"; estudo de casos; materiais visuais, como slides, fotografias, quadros, gráficos ou bases de dados; relatórios e problemas relacionados com a indústria agro-alimentar; pareceres técnicos [...]; material disponível em revistas e artigos publicados em revistas científicas (MOREIRA et al., 2009, p. 8).

Atividades estas que são objeto de discussão no seio do grupo de alunos e que podem "[...] obedecer a vários tipos de planos, nomeadamente: discriminação dos assuntos a discutir [...], sem que isso signifique rigidez ou inflexibilidade na discussão, mas clarificação de objetivos essenciais e tarefas" (MOREIRA et al., 2009, p. 9). Será a partir deste momento que, segundo Moreira, Teixeira, Valente (2005) e Moreira e colaboradores (2009) se passa da marcação de tarefas individuais, ao trabalho de pares, ao trabalho de grupo e à discussão na turma.

É no quadro deste conjunto de atividades que os autores defendem que a "utilização da plataforma de e-learning" (MOREIRA et al., 2009, p. 11) permite satisfazer os seguintes objetivos:

A aprendizagem de capacidades práticas e técnicas relevantes para o cálculo de necessidades nutriciais e formulação de ementas; analisar criticamente a literatura; identificar e saber abordar problemas novos; analisar e interpretar dados nutrio-alimentares disponíveis em Portugal e no mundo; desenvolver a criatividade e a capacidade de comunicação, nomeadamente a escrita. Aliás, reconhece-se que a dinamização da componente on-line numa disciplina pode incentivar atividades de aprendizagem de ordem superior, como seja o escrever, em oposição às tradicionalmente promovidas de ouvir e ler.

Como se pode concluir, este projeto distancia-se da perspetiva eficienticista porque, em primeiro lugar, se justifica pedagogicamente de forma cuidada as opções assumidas, não como opções inevitáveis mas como opções possíveis e desejáveis. De igual modo, distancia-se de uma abordagem em que as TIC são vistas como instrumentos propulsores da autossuficiência pedagógica e cultural dos alunos para serem abordadas, em vez disso, como ferramentas cujo impacto terá que ser compreendido de forma holística e sistémica, a partir das sinergias que se estabelecem entre as TIC e outros dispositivos de ação pedagógica. Neste sentido, o projeto A poderá ser enquadrado no "paradigma pedagógico da comunicação" (TRINDADE; COSME, 2010, p. 58), para o qual o desafio pedagógico maior que há que enfrentar é o da relação entre os estudantes e o 
património de informações, instrumentos, procedimentos e atitudes culturalmente validados e socialmente valorizados. Não se nega que a aprendizagem dos alunos é a maior preocupação das escolas, ainda que uma tal aprendizagem, porque conduz estes mesmos alunos a estabelecer confrontos epistemológicos com aquele património, obriga a que os professores, mais do que facilitadores, se assumam como "interlocutores qualificados" (COSME, 2009). Isto é, como alguém que se não prescreve modos de pensar e de agir também não se demite de gerir um processo de influência educativa que permita potenciar o protagonismo dos alunos a partir do seu envolvimento em projetos culturalmente significativos.

É esta última dimensão que se destaca no projeto da autoria de J. Villate (2005), em que a opção por utilizar as TIC é, mais do que uma opção técnico-pedagógica, uma opção que começa por se afirmar como uma opção epistemológica, através da qual se busca congruência entre o processo de formação e os objetos de saber que o justificam. Daí que seja um projeto que não se enquadra numa visão pedagogicamente eficienticista das TIC nem permita, por isso, que a sua mobilização como ferramenta pedagógica seja justificada, apenas, quer por via da sua alegada eficácia quer por via de uma visão epistemologicamente ingénua do seu impacto formativo.

Por sua vez, a importância do projeto protagonizado por F. Remião (2007) explica-se, entre outras razões passíveis de ser elencadas, pela estruturação de um ciclo didático através do qual se criam as condições para promover o coprotagonismo dos estudantes na apropriação do património de saberes e competências de uma área de formação, através de um processo de trabalho que implicava a atividade inteligente, intelectualmente desafiante e a cooperação entre os estudantes. Como no projeto de Moreira, Teixeira e Valente (2005) visa-se estimular e apoiar os estudantes a confrontar-se com problemas e informações credíveis através dos quais se dinamizaria um projeto de formação, assumindo as TIC um papel decisivo ao dinamizar um repositório, fóruns de discussão e plataformas virtuais onde se publicam estudos e resultados. Assim, utilizou-se a ferramenta Annoucements que "[...] foi importante não só para a resolução de questões práticas das aulas, como também para motivar o acesso dos alunos à plataforma” (REMIÃO, 2007, p. 8). O Chat, por sua vez, “[...] permitiu o esclarecimento de dúvidas", enquanto "[...] no fórum [...] foram lançados diversos desafios aos alunos, tais como a resolução de casos clínicos e forenses, a pesquisa de erros ou incorrecções científicas por parte do docente e a apresentação de dúvidas" (REMIÃO, 2007, p. 8).

O projeto dinamizado por P. Payo-Puente (2010), é o último dos projetos que apresentamos que não se enquadram na perspetiva eficienticista quer porque, apesar das referências à necessidade de, através do uso das TIC, se promover “[...] a rentabilidade pedagógica das experiências educativas” (PAYO-PUENTE, 2010, 
p. 4), se defende, acima de tudo, que o que se espera é não só “[...] conseguir a aquisição das habituais competências específicas relacionadas com a unidade curricular (conhecimento) mas promover ao mesmo tempo a aquisição de competências genéricas importantes (fundamentalmente trabalho em equipa)", criando-se "[...] as condições para atingir a aprendizagem em contexto prático de uma disciplina historicamente considerada como "exclusivamente teórica" (PAYO-PUENTE, 2010, p. 4). É a partir destes objetivos que se pretende, ainda, "[...] favorecer o contato dos alunos com a multifacetada realidade profissional", organizando-se, para além disso ou por causa disso, "[...] uma base de dados sobre casos clínicos reais" e, finalmente, estimular-se "[...] a capacidade de analisar a informação que obtemos de um animal vivo e relacioná-la com a informação proporcionada pelos livros" (PAYO-PUENTE, 2010, p. 4). Como se infere, o que se pretende é promover um projeto de formação que, de forma intencional e deliberada, se afaste de um modelo de formação escolástico para implementar um projeto que obrigou os estudantes a enfrentar problemas reais como condição das aprendizagens que estes deveriam realizar. Defrontamo-nos, assim, com uma iniciativa que se constrói não para rentabilizar, apenas, as aprendizagens dos estudantes mas para promover um conjunto de aprendizagens que se consideram pedagógicas e curricularmente necessárias. Por isso, Payo-Puente (2010, p. 10) defende que

[...] a utilização combinada de aulas presenciais com um ambiente virtual interativo permitiu uma maior colaboração e partilha de ideias entre alunos e professores, facilitou o acesso aos materiais de apoio ao estudo e dinamizou a procura de informação, quebrando-se assim a barreira espacial e temporal, até então condicionada às salas de aula e aos horários de atendimento. Além disso, tornou mais rápida a distribuição e explicação das tarefas a executar, permitiu ao docente um melhor acompanhamento dos trabalhos desenvolvidos e tornou a entrega de trabalhos e posterior avaliação por parte do docente mais eficaz.

Como se constata, a exemplo dos restantes três projetos que, na nossa opinião, não se subordinam à racionalidade de uma perspetiva eficienticista, este projeto é, igualmente, um projeto onde a dimensão do "Como fazer?" não só não ignora a dimensão do "Por que fazer?" como, sobretudo, acaba por se subordinar a esta dimensão. Por outro lado, estes quatro projetos não alimentam a possibilidade de entender os alunos como seres pedagógica e culturalmente autossuficientes, subestimando o papel dos professores por via da solução 
pedagógica que as TIC podem consubstanciar. Uma perspetiva que sustenta a proposta dos projetos que incluímos no campo delimitado pela perspetiva eficientista e que está na origem da crença que as TIC podem assumir uma função supletiva às aulas presenciais, defendendo que, através da sua utilização e gestão adequadas, é possível responsabilizar os estudantes pelas suas aprendizagens, permitindo alargar, assim, o espaço educativo disponível para além daquele que é delimitado, apenas, pelas aulas presenciais.

Não se pretende negar a importância que assume, hoje, a necessidade de promover a autonomia intelectual dos estudantes, ainda que seja necessário perguntar se essa autonomia se faz por via da ausência dos professores, passíveis de ser substituídos pelas TIC, ou, pelo contrário, se se constrói através de um certo tipo de presença docente que deixando de ser identificada com a instrução não tem que passar a ser entendida, apenas, como uma operação de facilitação pedagógica. Neste caso, e tal como já o defendemos, os docentes assumem-se como interlocutores qualificados (COSME, 2009) que, ao exercerem a sua função preocupados com a possibilidade do desenvolvimento da autonomia dos estudantes, intervêm de forma a promover tal autonomia como o resultado de um processo de formação e não tanto como uma condição prévia do mesmo. Cremos que os quatro últimos projetos apresentados e discutidos neste artigo constituem um exemplo de uma tal possibilidade, demonstrando, para além disso, a função que as TIC podem assumir neste âmbito. Estas tecnologias deixam de ser vistas como garantia dessa autonomia para passarem a ser abordadas como instrumentos que a permitem potenciar no quadro de ciclos didáticos que conferem sentido e significado ao processo da sua utilização.

\section{Conclusão}

Independentemente da importância e do impacto do nosso estudo, importa referir, como um fator fundamental do mesmo, que este se produziu a partir e em torno de projetos que foram entendidos, por especialistas externos, como projetos pedagógicos de referência. Neste caso, o valor do estudo tem mais a ver com a credibilidade dos projetos que foram objeto do mesmo do que com a sua representatividade. Daí que seja a partir desta condição que pensamos que este texto pode contribuir para a reflexão sobre a utilização pedagógica das TIC, já que nos permite estabelecer um confronto com perspetivas relevantes e distintas sobre esta utilização. 
Pudemos confirmar que estamos num campo marcado por tensões diversas, onde se pode constatar que a utilização pedagógica das TIC tanto pode "servir velhos modos de fazer" (PINHEIRO, 2012, p. 7) como pode contribuir para ampliar as possibilidades de partilha, de interlocução, de descoberta e de formação, sabendo-se que são as intenções, os pressupostos e os conceitos curriculares que modelam os ciclos didáticos e pedagógicos onde as TIC se enquadram que determinam o seu potencial pedagógico.

Pudemos defrontar-nos, também, com algumas questões que terão que merecer uma atenção mais cuidada da parte de todos nós, nomeadamente aquelas através das quais se identifica o estímulo à atividade dos alunos ou a ampliação dos espaços de partilha e de comunicação que as TIC proporcionam como iniciativas que garantem o protagonismo pedagógico dos estudantes e, deste modo, asseguram, só por si, que as TIC constituem um instrumento de empoderamento pedagógico. Como é possível compreender pelos dados e pela interpretação que, neste trabalho, produzimos acerca dos mesmos, nem aquela atividade dos alunos nem aquela ampliação dos espaços de partilha e de comunicação nos permite aceder a uma conclusão tão perentória. O protagonismo pedagógico dos alunos é um objetivo mais complexo que depende não tanto da atividade em si, mas dos pressupostos, dos objetivos e das condições que norteiam essa atividade. Como se pode afirmar o mesmo acerca da ampliação dos espaços de partilha e de comunicação, isso significa que o que neste texto temos vindo a identificar por perspetiva eficienticista deve ser entendido ou como uma perspetiva que ao contribuir para a modernização do paradigma da instrução contribui para o legitimar e tornar aceitável, ou como um obstáculo concetual que, de algum modo, obscurece a reflexão sobre o papel das TIC no processo de transição para o que Trindade e Cosme (2010) designam por paradigma da comunicação.

No estudo que acabamos de divulgar alguns projetos enquadram-se na abordagem que a perspetiva eficienticista promove, outros podem ser vistos como possíveis manifestações de iniciativas que, pese as suas eventuais hesitações e contradições, se aproximam dos pressupostos do já referido projeto de comunicação. Nesta reflexão, como em qualquer outra reflexão pedagógica, não se trata de saber quais as estratégias mais eficazes, mas tão somente de identificar aquelas que são as mais interessantes, do ponto de vista do que pretendemos com o nosso envolvimento, enquanto docentes, num ato de fomação. 


\section{ANEXO 1}

\begin{tabular}{|c|c|c|}
\hline Autores & Título & Caraterização sumária \\
\hline $\begin{array}{l}\text { Moreira, Teixeira } \\
\text { \& Valente }(2005)\end{array}$ & $\begin{array}{l}\text { E-Learning em alimentação } \\
\text { e nutrição humana durante } \\
\text { o ano lectivo de 2004/2005 }\end{array}$ & $\begin{array}{l}\text { Este é um projeto que se desenvolveu } \\
\text { na Faculdade de Ciências da Nutrição } \\
\text { e Alimentação da Universidade do } \\
\text { Porto, onde se descreve e reflete sobre a } \\
\text { integração das TIC nas aulas teóricas, nas } \\
\text { aulas teórico-práticas e nas aulas práticas. }\end{array}$ \\
\hline Villate (2005) & $\begin{array}{l}\text { E-Learning na } \\
\text { Universidade do Porto - } \\
\text { Caso de Estudo: Física dos } \\
\text { Sistemas Dinâmicos }\end{array}$ & $\begin{array}{l}\text { Este é um projeto que se desenvolveu na } \\
\text { Faculdade de Engenharia da Universidade } \\
\text { do Porto, através do qual se defende a } \\
\text { necessidade de estabelecer um ensino } \\
\text { congruente com o peso das TIC na } \\
\text { disciplina em causa. }\end{array}$ \\
\hline $\begin{array}{l}\text { Andrade, Valentão } \\
\& \text { Amaral (2006) }\end{array}$ & $\begin{array}{l}\text { Farmacognosia II - } \\
\text { E-Learning, nova estratégia } \\
\text { de ensino }\end{array}$ & $\begin{array}{l}\text { Este é um projeto que se desenvolveu na } \\
\text { Faculdade de Farmácia da Universidade } \\
\text { do Porto, onde se descreve e reflete sobre } \\
\text { o espaço das TIC nas aulas teóricas e } \\
\text { laboratoriais. }\end{array}$ \\
\hline Vasconcelos (2006) & $\begin{array}{l}\text { Matemática I - Estudo de } \\
\text { caso: Projeto E-Learning } \\
\text { UP (Universidade do Porto) / } \\
\text { 2005-2006 }\end{array}$ & $\begin{array}{l}\text { Este é um projeto que se desenvolveu na } \\
\text { Faculdade de Economia da Universidade } \\
\text { do Porto, através do qual se pretende } \\
\text { complementar as aulas presenciais com a } \\
\text { parte on-line do curso. }\end{array}$ \\
\hline Remião (2007) & $\begin{array}{l}\text { Ensino da Toxicologia } \\
\text { no âmbito do Projeto } \\
\text { E-Learning UP }\end{array}$ & $\begin{array}{l}\text { Este é um projeto que se desenvolveu na } \\
\text { Faculdade de Farmácia da Universidade } \\
\text { do Porto onde de descreve e reflete sobre a } \\
\text { utilização transversal das TIC. }\end{array}$ \\
\hline Ribeiro et al. (2008) & $\begin{array}{l}\text { Anatomia Clínica on-line: } \\
\text { De repositório a estação de } \\
\text { treino virtual. }\end{array}$ & $\begin{array}{l}\text { Este é um projeto que se desenvolveu na } \\
\text { Faculdade de Medicina da Universidade } \\
\text { do Porto onde se descreve e reflete sobre a } \\
\text { utilização pedagógica de uma plataforma } \\
\text { virtual }\end{array}$ \\
\hline Oliveira (2008) & $\begin{array}{l}\text { O E-Learning como } \\
\text { instrumento promotor da } \\
\text { dinâmica de grupos e da } \\
\text { aprendizagem contínua: } \\
\text { O caso da Farmacologia } \\
\text { da FFUP (Faculdade de } \\
\text { Farmácia da Universidade } \\
\text { do Porto) }\end{array}$ & $\begin{array}{l}\text { Este é um projeto que se desenvolveu na } \\
\text { Faculdade de Farmácia da Universidade } \\
\text { do Porto, onde se descreve e reflete sobre } \\
\text { a importância das TIC na dinâmica dos } \\
\text { grupos, na promoção da aprendizagem } \\
\text { contínua, na gestão do acompanhamento } \\
\text { dos estudantes e no processo de avaliação. }\end{array}$ \\
\hline
\end{tabular}


(conclusão)

\begin{tabular}{|c|c|c|}
\hline $\begin{array}{l}\text { Ferreira \& Amaral } \\
\text { (2009) }\end{array}$ & $\begin{array}{l}\text { Estratégias de ensino e } \\
\text { avaliação em contexto on- } \\
\text { line aplicado à Alimentação } \\
\text { Humana: Contributo para } \\
\text { os princípios de Bolonha. }\end{array}$ & $\begin{array}{l}\text { Este é um projeto que se desenvolveu na } \\
\text { Faculdade de Farmácia da Universidade } \\
\text { do Porto onde se descreve e reflete sobre a } \\
\text { utilização de uma plataforma virtual e de } \\
\text { dois jogos virtuais. }\end{array}$ \\
\hline $\begin{array}{l}\text { Moreira et al. } \\
\text { (2009) }\end{array}$ & $\begin{array}{l}\text { Development and } \\
\text { evaluation of a web-based } \\
\text { game to teach immunology } \\
\text { content to medical } \\
\text { students. }\end{array}$ & $\begin{array}{l}\text { Este é um projeto que se desenvolveu na } \\
\text { Faculdade de Medicina da Universidade } \\
\text { do Porto onde se descreve o impacto de } \\
\text { um jogo virtual. }\end{array}$ \\
\hline Payo-Puente (2010) & $\begin{array}{l}\text { Caso de estudo: Patologia } \\
\text { Clínica de Animais de } \\
\text { Companhia (Módulo } \\
\text { I). Projeto Pratic's: TIC } \\
\text { num sistema Web } 2.0 \\
\text { como catalisador do } \\
\text { trabalho colaborativo, das } \\
\text { experiências de tipo prático } \\
\text { e da contextualização } \\
\text { profunda das aprendizagens }\end{array}$ & $\begin{array}{l}\text { Este é um projeto que se desenvolveu no } \\
\text { Instituto de Ciências Biomédicas de Abel } \\
\text { Salazar da Universidade do Porto, onde } \\
\text { de descreve e reflete sobre a utilização } \\
\text { transversal das TIC. }\end{array}$ \\
\hline $\begin{array}{l}\text { Moura, Amaral \& } \\
\text { Severo (2011) }\end{array}$ & $\begin{array}{l}\text { Equiparação de pontuações } \\
\text { de testes feitos em } \\
\text { computador por pequenos } \\
\text { turnos de estudantes }\end{array}$ & $\begin{array}{l}\text { Este é um projeto que se desenvolveu na } \\
\text { Faculdade de Medicina da Universidade } \\
\text { do Porto onde se descreve uma } \\
\text { intervenção no domínio da avaliação. }\end{array}$ \\
\hline
\end{tabular}

\section{REFERÊNCIAS}

ANDRADE, P. A.; VALENTÃO, P.; AMARAL, M. Farmacognosia II - E-Learning, nova estratégia de ensino. 2006. Disponível em: <https://elearning.up.pt $>$. Acesso em: 03 mar. 2014.

CORREIA, J. A. Inovação pedagógica e formação de professores. Porto: Edições ASA, 1989.

COSME, A. Ser professor: A acção docente como uma acção de interlocução qualificada. Porto: LivPsic, 2009.

FERREIRA, I. M. P. L. V. O.; AMARAL, M. Estratégias de ensino e avaliação em contexto on-line aplicado à Alimentação Humana: Contributo para os princípios de Bolonha. 2009. Disponível em: <https://elearning.up.pt>. Acesso em: 03 mar. 2014.

HARLAND, T. Zoology students: Experiences of collaborative enquiry in Problem-based learning. Teaching in Higher Education, v. 7, n. 2, p. 03-15, 2002. 
KNOWLES, M. S. Andragogy in action. S. Francisco: Jossey-Bass, 1984.

LEITE, C.; LIMA, L.; MONTEIRO, A. O trabalho pedagógico no Ensino Superior: Um olhar a partir do prémio Excelência E-learning da Universidade do Porto. Educação, Sociedade \& Culturas, n. 28, p. 71- 91, 2009.

MOREIRA, A.; SANTOS, C.; MACEDO, P.; MONTEIRO, P.; FERNANDES, R.; MOTA, S.; SILVA, S.; DELGADO, L. Development and evaluation of a web-based game to teach immunology contente to medical students. 2009. Disponível em: $<\mathrm{https}: / /$ elearning.up.pt>. Acesso em: 03 mar. 2014.

MOREIRA, P.; TEIXEIRA, V.; VALENTE, H. E-Learning em alimentação e nutrição humana durante o ano lectivo de 2004/2005. 2005. Disponível em: <https://elearning. up.pt>. Acesso em: 03 mar. 2014.

MOURA, D.; AMARAL, M.; SEVERO, M. Equiparação de pontuações de testes feitos em computador por pequenos turnos de estudantes. 2011. Disponível em: $<$ https:// elearning.up.pt>. Acesso em: 03 mar. 2014.

OLIVEIRA, J. M. A. O E-Learning como instrumento promotor da dinâmica de grupos e da aprendizagem contínua: O caso da Farmacologia da FFUP. 2008. Disponível em: $<$ https://elearning.up.pt>. Acesso em: 03 mar. 2014.

PAYO-PUENTE, P. Caso de estudo: Patologia Clínica de Animais de Companhia (Módulo I). Projeto Pratic's: TIC num sistema Web 2.0 como catalisador do trabalho colaborativo, das experiências de tipo prático e da contextualização profunda das aprendizagens. 2010. Disponível em: <https://elearning.up.pt>. Acesso em: 03 mar. 2014.

PINHEIRO, A.Cruz@r educadoresna Internet. Porto: LivPsic, 2012.

REMIÃO, F. Ensino da Toxicologia no âmbito do Projeto E-Learning UP. 2007. Disponível em: <https://elearning.up.pt>. Acesso em: 03 mar. 2014.

RIBEIRO, M.; AMARAL, M.; RIBEIRO, H.; DINIS-MACHADO, J.; POVO, A.; MILTON, S.; TAVARES, M. A. F. Anatomia Clínica on-line: De repositório a estação de treino virtual. 2008. Diponível em: <https://elearning.up.pt>. Acesso em: 03 mar. 2014.

TRINDADE, R.; COSME, A. Escola, educação e aprendizagem: Desafios e respostas pedagógicas. Rio de Janeiro: WAK editora, 2010.

VASCONCELOS, P. B. Matemática I - Estudo de caso: Projeto E-Learning UP/20052006. 2006. Disponível em: <https://elearning.up.pt>. Acesso em: 03 mar. 2014.

VILLATE, J. E. E-Learning na Universidade do Porto - Caso de Estudo: Física dos Sistemas Dinâmicos. 2005. Disponívelem: <https://elearning.up.pt>. Acesso em: 03 mar. 2014.

ZABALA, A. A prática educativa: Como ensinar. Porto Alegre: Artmed, 1998.

Texto recebido em 22 de novembro de 2014.

Texto aprovado em 11 de dezembro de 2014. 
